\title{
EUGENIA NEGATIVA/POSITIVA: O SUPOSTO COLAPSO DA NATUREZA EM J. HABERMAS
}

\author{
José Nicolau Heck*
}

RESUMO - Há muito tempo o progresso científico provoca nossas convicções e ameaça deixar o discurso moral para trás. Mais recentemente, a polêmica em torno da permissão ou proibição da eugenia negativa e positiva questiona nossa autocompreensão de natureza, moralidade e liberdade. O presente texto tem por objeto uma série de artigos de J. Habermas, convertidos posteriormente em livro, onde são expostos argumentos fortemente plausíveis em favor da tese da indisponibilidade da natureza humana no âmbito da eugenia positiva. Após contextuar o problema e mapeá-lo no horizonte filosófico, o trabalho apresenta a posição metafísica habermasiana, com destaque para a distinção entre eugenia negativa e positiva, e a confronta com os argumentos liberais dworkinianos acerca do tema. O artigo pleiteia a favor da tese de que a naturalidade humana consiste, desde os primórdios da espécie, em autocriação natural, de modo que cabe à moralidade e ao direito preencherem o vácuo do destino criado pela biotecnologia.

PALAVRAS-CHAVE - Natureza humana. Habermas. Eugenia negativa e positive. Ética. Filosofia do direito.
ABSTRACT - For a long time scientific progress has been challeging our moral convictions, bringing the threat of making moral discourse totally surpassed. More recently the controversy around the permission or prohibition of negative and positive eugeny questions our selfunderstanding of nature, morality and freedom. The text has as its object several articles of $\mathrm{J}$. Habermas, which turned afterwards into a volume, where the author exposes strongly plausible arguments for the thesis of the unavailability of human nature in the field of positive eugeny. After contextualising the problem and mapping it in the scientific horizon, the study presents Habermas's metaphysical account, putting emphasis on the distinction between negative and positive eugeny, and confronts that same account of Habermas with Dworkin's liberal arguments about the topic. The article pleads for the thesis that human naturality consists since the beginning of humanity in natural self-creation, so that it is a task of morality and science of law to fulfill the empty space of the destiny built up by biotechnology.

KEY WORDS - Human nature. Negative and positive eugeny. Philosophy of law.

* Professor da UFG e da UCG e Pesquisador do CNPq.

\begin{tabular}{|l|l|l|l|l|l|}
\hline VERITAS & Porto Alegre & v. 51 & n. 1 & Março 2006 & p. 42-55 \\
\hline
\end{tabular}




\section{Introdução}

Por mais sugestivos que os neologismos da medicina reprodutiva sejam, a terminologia biotecnológica da reprodução assistida ${ }^{1}$ continua ter por referência o que consideramos vida e não o que ela é em si mesma. Na medida em que a vida se manifesta na forma como cada um a percebe e/ou a percebemos de forma coletiva, o início e o fim da mesma equivalem a demarcações que estabelecem a partir de quando e até quando queremos admitir, respeitar e proteger algo como ser vivo. O restante é natureza morta.

Por não haver possibilidade de dissociar o que consideramos vida de um conjunto variável de características biológicas, os avanços das ciências biológicas alteram cenários de origem que há milênios configuram o início da vida humana. Vivenciar a gravidez com óvulos doados não mais assegura a ligação genética da criança à mãe e, inversamente, a gravidez de aluguel dá à mãe legal a oportunidade de ter um filho geneticamente ligado ao parceiro.

Há tempo a biologia não mais é considerada uma ciência do destino, quer dizer, não se entende mais como caudatária da natureza, à revelia do conhecimento e de suas virtualidades tecnológicas. Nossa constituição genética começa a ficar ao alcance da mão. As fatalidades oriundas de tempos imemoriais dão lugar a opções; essas não mais necessitam de aceitação, mas exigem que sejam ponderadas. Aquilo que há pouco tempo crescia sem nossa ajuda pode agora ser feito por nós e assume as configurações que lhe concedemos, o que pode dar, erroneamente, a impressão de que os humanos terão em breve um genótipo rigorosamente determinado pelos pais, mantido inalterável vida afora, ininfluenciável a qualquer ambiente e resistente a toda forma de interação com o meio.

\section{Habermas e a eugenia}

Assim como as técnicas de fecundação e implantação solucionam problemas de infertilidade, a biópsia de embriões e o diagnóstico genético pré-implantacional têm condições de intervir em células germinativas e sustar doenças incuráveis. A tecnociência de manipulação das células-tronco embrionárias fornece a matriz da eugenia negativa, cuja panacéia tecnológica promete refazer qualquer tecido celular doente, dos traumas da medula espinhal aos infartos do miocárdio. Produzido por fertilização in vitro, o zigoto (célula resultante da fertilização do gameta feminino pelo masculino) é cultivado até alcançar o estágio de blastocisto (zigoto com estrutura de préembrião); de seu miolo extraem-se células-tronco embrionárias que liberam as linhagens para diagnósticos e pesquisas de terapia voltadas para o suprimento de cirurgias de transplante, a eliminação de doenças hereditárias e proporcionam, eventualmente, vida saudável ao nascituro via correção do seu patrimônio genético. ${ }^{2}$

1 Inseminação intra-uterina/intracervical de espermatizóides; fertilização in vitro convencional; injeção intracitoplasmática de espermatozóides, eventualmente combinada com obtenção de espermatozóides do epidídimo e testículo. Diagnóstico genético pré-implantação.

A extração das células-tronco que originam as linhagens para pesquisas de terapias do interior do blastocisto não destrói necessariamente a composição celular do embrião. Cf. LANZA, Robert et al. 
A invenção e a disseminação de testes e intervenções biomédicas para avaliar riscos e evitar a gestação de fetos com síndrome de Down ou de outros desvios físicos e retardos mentais amplia, por um lado, as fronteiras da eugenia e traz de volta, por outro, o espectro nazista da purificação da raça ariana. À primeira vista, parece razoável limitar o termo "eugenia" a políticas públicas que buscam interferir em aspectos étnicos ou raciais da população e enquadrar, em contrapartida, o diagnóstico pré-natal extracorporal nos direitos individuais de obter informações e poder decidir a bel-prazer o que fazer com elas. Basta, porém, atentar que os milhões de mortos pelos regimes totalitários do século XX eram vistos como indignos à luz das doutrinas racistas ou revolucionárias de seus algozes para suspeitar que exista algum tipo de incompatibilidade entre dignidade humana e manipulação genética, quer autoritária, quer liberal.

A eliminação radical da eugenia vai, por sua vez, de mãos dadas com a radicalização ecológica de proteger a natureza das intervenções da ciência, da técnica e da economia. Enquanto a crítica ecológica à civilização é abrangente, a desconfiança para com as técnicas eugenéticas limita-se a manter a natureza humana o mais possível separada da manipulação biotecnológica. Na medida em que o debate genético herda a posição dos movimentos ecológicos, a crítica às práticas eugênicas é feita em nome da indisponibilidade técnica da espécie humana em seu todo. O claro-escuro que distingue o que somos naturalmente e o que é inovação em nós induz uma cultura de vulnerabilidade que justifica toda sorte de regulamentação e protege, assim, a prole na condição de vítima das presumidas motivações corretivas e dos anseios transformistas dos respectivos progenitores. Segundo E. Lee, da Universidade de Southampton, responsáveis por essa postura defensiva perante a eugenia são dialéticos progressistas convertidos ao ambientalismo, zelosos pela ambivalência frente à tecnização geral da natureza externa e perante a tecnização específica da natureza interna. ${ }^{3}$

A reserva doutrinária mais sólida do ambientalismo normativo oferecem as tradições do jusnaturalismo e do objetivismo axiológico. Ambos constituem vertentes filosóficas da indisponibilidade natural de valores com caráter ontológico, aderência absoluta e substancialidade normativa, antípodas declarados da versão hobbesiana, marxiana e weberiana do conceito de valor. O recurso à chamada ética

Embryonic and extraembryonic stem cell lines derived from single mouse blastomeres. In: Nature, 439, 2006, p. 216: "Here we report an alternative method of establishing ES cell lines - [...] - that does not interfere with the developmental potential of embryos". Cf. também GUAN, K. et al. Nature, 440, 2006

3 LEE, Ellie. Debating 'designer babies'. “Today's society is experiencing a growing anxiety about our ability to cope with innovation. Change tends to be viewed in a very one-sided way, as something that is likely to bring about harm. There is a sensibility that if we innovate, it will generate unforeseen problems and dangers that we will not be able to cope with [...]. [... today's opposition to new reproductive technologies is often articulated by those who consider themselves radical environmentalists, certain strands of feminist opinion, or some parts of the disability rights lobby. Far from being marginalized, these views have a wide resonance with an elite that is increasingly ambivalent about innovation and change. Perhaps this helps to explain why fears about 'designer babies' are entertained" (www.nature.com/nature/journal/vaop/ncurrent/index.html - acesso em 02.03.06). 
material implica, segundo W. Kersting, que seja decretado "um direito ao crescimento natural, à inviolabilidade das características naturais, à identidade não-planejada, à imperfeição". ${ }^{4}$ As consequiências de um recuo àquilo que é indisponível por natureza faz com que "[o] direito humano transforma-se novamente em direito natural; e ações da medicina reprodutiva e da tecnologia genética adquirem a qualidade de peccata contra naturam". 5

A disponibilização científica e a subseqüente violação técnica dos bens naturais, por meio da micromanipulação de gametas post fertilisationem, violam, segundo Habermas, a ordem natural, quando escreve: "Elas [as técnicas de seleção genética] colocam à disposição qualquer base física, 'a que somos por natureza". ${ }^{6}$ O pensador alemão invoca Kant para concluir que a pesquisa biotecnológica amplia de tal maneira a natureza 'interna' das opções humanas a ponto de alterar o conjunto de nossa experiência moral. Em face de tal deferência, W. Kersting apostrofa: "A situação não deixa de ser paradoxal: uma naturalidade do ser humano, considerada moralmente significativa, é mobilizada contra as conseqüências tecnológicas da naturalização científica do ser humano". ${ }^{7}$

O descarte de alternativas pré-modernas, para lidar adequadamente com as técnicas de intervenção no genoma humano, desafia sobremodo autores como J. Habermas cuja versatilidade moderna está acima de qualquer suspeita, cuja relação com a tradição filosófica permanece indizível e cuja ética do discurso tem sempre algo a contribuir com debates que ofereçam a oportunidade de representar ofensivamente o curso filosófico da modernidade. ${ }^{8}$ A identificação do problema, a formulação de alternativas e a caracterização de hipóteses remetem, no universo biotecnológico habermasiano, a uma autocompreensão compacta de natureza humana. Privilegiada é a base física, o destino biológico, as feições corporais, o destino natural da espécie humana. O filósofo alemão passa ao largo das diferentes acepções de natureza humana, privilegia uma concepção tética de natura, munida de virtualidades mutacionais e centrada pelo referencial dialético-transformista hegeliano que, em sua plenitude lógico-metafísica, coalesce natureza interna e natureza externa e reduz o domínio fenótipo à carga genética de seres humanos in spe.

4 KERSTING. "[...] wird ein Recht auf Naturwüchsigkeit, auf Unantastbarkeit der natürlichen Prägung, auf ungeplante Identität, auf Unvollkommenheit dekretiert”. Der Hüter der Moderne Jürgen Habermas über die Vergangenheit des Nationalstaates und die Zukunft der Natur, p. 87.

5 Ibidem. "Das Menschenrecht wird wieder zum Naturrecht; und reproduktionsmedizinische und gentechnische Handlungen gewinnen die Qualität von peccata contra naturam".

6 HABERMAS. Jürgen. Die Zukunft der menschlichen Natur, p. 53. "Sie stellen jene physische Basis, , die wir von Natur aus sind', zur Disposition”.

7 KERSTING. Op. cit., p. 87. "Die Situation entbehrt nicht der Paradoxie: Eine als moralisch bedeutungsvoll angesehene Natürlichkeit des Menschen wird gegen die technologischen Folgen der wissenschaftlichen Naturalisierung des Menschen in Stellung gebracht".

8 Ibidem, p. 81. "Jürgen Habermas ist nie ein Buchhalter der Letztbegründung gewesen. Seine Diskursethik war dazu immer zu wendig und zu neugierig. Wo immer sich neue Probleme zeigen, eilt sie herbei, um sich zu bewähren und ihr emanzipatorisches Potencial zur Geltung zu bringen. Wo immer sich neue Debatten regen, meldet sie sich zu Wort, um energisch die Sache der Moderne zu vertreten". 


\section{Natureza, Moral e Dialética}

Habermas ignora qualquer tipo de amparo ontológico de valores, rejeita a posição eugênica liberal e não aplica a teoria da ação comunicativa ao complexo biotecnológico. Seu argumento-chave é a natureza despida de teorias, proposituras ou divagações antropológicas clássicas, medievais ou modernas. ${ }^{9}$

O filósofo do discurso desconhece indícios que distinguem a natureza dos humanos da natureza não-humana; tampouco confere atenção para fenômenos naturais que se nos afiguram desnaturados, anormais ou artificiais; em momento algum aponta para qualidades que indiciam universalidade, releva traços ou atitudes que caracterizam marcos transhistóricos da natureza humana; o pensador pós-frankfurtiano passa igualmente ao largo da evolução de estirpe darwiniana e do materialismo de cunho marxiano, nas contribuições que ambas as doutrinas deram para o esclarecimento das relações entre homens e animais. O dialético de outrora também não chega a ressaltar o corpo humano como produto da seleção natural e ignora a corporeidade como limite natural da variabilidade social do ser humano.

A proposta habermasiana de moralizar a natureza humana, isto é, tornar normativamente indisponível o que supõe naturalmente não-disponível remoraliza de forma explícita o que, ao longo da modernidade, foi paulatinamente desapropriado de caracteres morais. Na ausência de uma consistente razão prática, a estratégia de tornar intocável pela moral o que supostamente esteve confiado à natureza qua acaso legitima tardiamente a passividade racional, na qual Kant vê latejar a heteronomia da razão e à qual chama de preconceito. O inveterado iluminista alemão insiste, ao escrever: "[e]o maior de todos eles é o de representar-se a natureza como não submetida a regras que o entendimento por sua própria lei essencial põe-lhe como fundamento, isto é, a superstição"; e arremata: "[l]ibertação da superstição chama-se Esclarecimento". ${ }^{10}$

A detalhada problematização, feita por Habermas da proposta liberal, procura superar ao mesmo tempo as dificuldades que a ética do discurso encontra no âmbito teórico da biotecnologia, no universo das práticas eugênicas e na esfera da aplicação jurídica, tendo em vista que o embrião permanece excluído, na condição de não-ente jurídico, do discurso, das ponderações e da decisão que lhe predica indisponibilidade. Com a tese de que "[...] algo pode ser considerado 'indisponível', ainda que não receba o status de um sujeito de direitos [...]", ${ }^{11}$ Habermas não apenas supera dialeticamente aqueles que tomam o embrião em estágio prematuro por um "amontoado de células" e sobrepuja reflexivamente quem considera o mesmo como uma "pessoa em potencial", mas também suprassume a ética discursiva na participação de algo que não usufrui de

9 CF. JAGGAR, Alison \& STRUHL, Karsten. Human Nature. In: Encyclopedia of Bioethics. Ed. by Stephen G. Post. 3rd ed. New York: Macmillan, p. 1209-1221.

10 KANT. Immanuel. Kritik der Urteilskraft 158. Hrsg. von K. Vorländer. Hamburg: F. Meiner, 1968, p. 145. "[und] das grösste unter allen ist, sich die Natur Regeln, welche der Verstand ihr durch sein eigenes wesentliches Gesetz zum Grunde legt, als nicht unterworfen vorzustellen, d.i. der Aberglaube. Befreiung vom Aberglauben heisst Aufklärung".

11 HABERMAS. Op. cit., p. 59. "[...] etwas als 'unverfügbar' gelten kann, auch wenn es nicht den Status einer Rechtsperson einnimmt [...]". 
direitos para, mesmo assim, figurar num logos abrangente que the assegura o destino jurídico e uma história de vida.

Como, de acordo com o artigo 1 da Constituição alemã, os direitos fundamentais são constitutivos da dignidade humana (Menschenwürde), Habermas não tem como evadir-se da dialética natural dos "bons motivos morais" (aus guten moralischen Gründen), uma vez que as premissas do agir comunicativo, do reconhecimento recíproco e da ética do discurso permanecem sem ação na malha argumentativa do cenário bioético e biopolítico dos embriões humanos. ${ }^{12}$ À luz das interpretações constitucionais alemães recentes acerca da dignidade humana como direito fundamental, a tese de Habermas é anacrônica em acepção jurídica, ou seja, nenhum direito fundamental é visto de maneira isolada, mas em conexão e ou em concorrência com os demais direitos fundamentais. Em outras palavras, os bons motivos morais não substituem, num estado de direito, a interpretação ponderada do direito da dignidade humana no âmbito da respectiva constituição. ${ }^{13}$

O fato kantiano da razão, descartado por Habermas já nos idos dos anos sessenta, metamorfoseia-se tardiamente em autocompreensão ética da espécie, o que ratifica a avaliação de J. Rawls, quando este observa que "a doutrina de Habermas constitui uma doutrina da lógica no sentido lato hegeliano". "Vista a partir da síntese, à natureza cabe em Habermas o que é obra do espírito em Hegel, isto é, anterior a qualquer qualificação jurídica, a natureza habermasiana guarda ab initio o suposto segredo normativo do télos da espécie; tomada por tese, a natureza providencia em Habermas o que o ser e o nada hegelianos operam no quilômetro zero da lógica, ou seja, na origem do homem o genótipo e o fenótipo são domínios habermasianos conversíveis da natureza humana e, como tais, imperceptíveis em sua alteridade.

O preço que Habermas tardiamente paga pela superação do Faktum kantiano é a necessidade teórica de alterar os quadros da moral sempre quando os supostos limites do acaso e da liberdade são deslocados.

Enquanto com os métodos usuais de inseminação só é possível torcer para que as condições saudáveis e os traços tidos como vantajosos do esperma do doador escolhido sejam transmitidos ao embrião, o diagnóstico genético pré-implantacional oferece a possibilidade de avaliar distintos cromossomos com vistas a anomalias, como a trissomia que leva à síndrome de Down e a hemofilia na determinação do sexo, e permite registrar, com um crescente grau de segurança, a presença de alelos gênicos relacionados à atrofia espinhal progressiva, às distrofias musculares e à fibrose cística.

Embora as intervenções de caráter eugênico negativo, terapêutico, clínico ou curativo, subseqüentes ao diagnóstico genético pré-implantação, alterem a presumida ordem preestabelecida do patrimônio genético natural do feto, há um consenso generalizado de que estão a limine justificadas pelo assentimento posterior da prole,

12 FORST, Rainer. Die Würde des Menschen und das Recht auf Rechtfertigung. DZPhil. Berlin 53 (2005) 4, 589-596.

13 BAER, Susanne. Menchenwürde zwischen Recht, Prinzip und Referenz. DZPhil. Berlin 53 (2005) 4, 571-588.

14 RAWLS, John. Reply to Habermas. In: Political liberalism. New York: Columbia University Press, 1993, p. 378. "Habermas's own doctrine, I believe, is one of logic in the broad Hegelian sense [...]". 
uma vez que é sensato admitir que seres humanos desejam não ter disposições patológicas monogenéticas. Em relação à eugenia negativa não há, assim, controvérsias maiores quanto ao uso das técnicas disponíveis que impedem o nascimento de seres humanos onerados com deficiências graves, ou seja, aqui como alhures não há muita celeuma quando se trata de evitar o pior, o defeituoso, o que causa sofrimento e/ou traz infelicidade.

Também Habermas distingue entre eugenia negativa e positiva. Ele admite a admissibilidade da primeira com base em dispositivos legais "que restrinjam o direito fundamental a um patrimônio hereditário não-manipulado, se a ponderação moral e a formação democrática da vontade conduzam a esse resultado". 15 O princípio da admissão da eugenia negativa opera com a plausibilidade antecipada dos pais em admitir o acordo do futuro rebento em favor de uma intervenção genética capaz de sustar a possível transmissão de disposições patológicas. "Essa atitude clínica recebe sua força legitimadora", escreve Habermas, "da suposição contrafactual e justificada de um possível consenso com o outro, que pode dizer 'sim' ou 'não'. Com isso, o ônus normativo da prova "recai aqui sobre o direito de antecipar um consentimento que não pode ser obtido no momento". ${ }^{16}$ A exceção feita coincide com o senso comum quando exclui, como anormais, atitudes que preferem doenças à saúde, o que não pode, por sua vez, ser admitido no âmbito da eugenia positiva, dada a ausência de um padrão universal de preferências eugênicas saudáveis à disposição dos progenitores do nascituro.

Em outras palavras, a eugenia negativa distingue-se, por um lado, da eugenia positiva pela diferença entre preferências a serem evitadas, passíveis de generalização, e, por outro, graças a preferências de otimização não-generalizáveis. ${ }^{17}$ Ao escaparem do discernimento entre ser e dever ser, as últimas permanecem indisponíveis graças à remoralização da natureza. Segundo Habermas, o conhecer e o agir encontram-se embutidos numa ética da espécie humana; torná-la disponível significaria o abandono do substrato natural da moralidade e do direito, da dignidade humana e do direito humano, ${ }^{18}$ ou na formulação de Volpato Dutra: "Mexer na natureza humana altera o auto-entendimento do homem como eticamente livre e moralmente guiado por normas". ${ }^{19}$

15 HABERMAS. Op. cit., p. 51. "Diese könnte gegebenfalls, wenn moralische Abwägung und demokratische Willensbildung zu diesem Ergebnis führen sollten, ein Grundrecht auf unmanipulierte Erbanlagen gesetzlich einschränken".

16 Ibidem, p. 78-79: "Diese klinische Einstellung bezieht ihre legitimierende Kraft aus der begründeten kontrafaktischen Unterstellung eines möglichen Konsenses mit einem Anderen, der Ja oder Nein sagen kann. Damit verschiebt sich die normative Beweislast auf die Berechtigung zur Antizipation 17 einer Zustimmung, die aktuell nicht eingeholt werden kann".

17 Ibidem. "Jedenfalls kann sich ein unterstellter Konsens nur auf die Vermeidung unzweifelhafter extremer Übel beziehen, die, wie erwartet werden kann, von allen abgelehnt werden".

18 Ibidem, p. 74. "Aus dieser Perspektive drängt sich die Frage auf, ob die Technisierung der Menschennatur das gattungsethische Selbstverständnis in der Weise verändert, dass wir uns nicht länger als ethisch freie und moralisch gleiche, an Normen und Gründen orientierte Lebewesen verstehen können".

19 VOLPATO DUTRA, Delamar J. Razão e consenso em Habermas, p. 260. 


\section{Contra-argumentos}

No extremo oposto, Dworkin classifica a posição ostensivamente avessa do parlamento europeu à clonagem de embriões humanos, em nome dos direitos fundamentais, como retórica ${ }^{20}$ e grotesca, ${ }^{21}$ para perguntar:

qual é a diferença, afinal, entre inventar penicilina e usar genes produzidos e clonados para curar doenças ainda mais terríveis daquelas curadas pela penicilina? Qual a diferença entre submeter sua criança a exercícios extenuantes, para reduzir seu peso ou aumentar sua força, e alterar, com o mesmo objetivo em mente, os seus genes enquanto um embrião? ${ }^{22}$

Habermas ${ }^{23}$ cita o contraente estadunidense em seu favor quando este distingue "entre o que somos responsáveis por fazer ou decidir, individual ou coletivamente, e o que nos é dado como fundamento contra o qual decidimos, mas somos incapazes de mudar" ${ }^{24}$ para, de imediato, registrar que considera ousada a afirmação dworkiniana de que o conjunto da estrutura de nossa experiência moral possa vir a ser alterada por intervenções eugênicas.

Esse é o pomo de discórdia entre a noção liberal e a percepção natural de eugenia. À luz dos critérios aduzidos por Dworkin, o núcleo duro do arrazoado habermasiano está na percepção filosófica diante da suposta ameaça da biotecnologia à natureza do indivíduo enquanto membro do gênero humano, ou seja, a eugenia positiva incide, segundo Habermas, sobre "o modo como nos entendemos antropologicamente enquanto seres da espécie", ${ }^{25}$ vale dizer, para o outrora crítico contumaz do positivismo nas ciências naturais os seres humanos acabarão, num futuro próximo, necessariamente determinados pelos mecanismos artificiais da biotecnologia reprodutiva. Na verdade, o filósofo alemão é vítima de um conseqüencialismo lapidar: sua concepção intrinsecamente sustentável de natureza humana independe de criação, ambiente, alternativas comportamentais, educação e toda sorte de dados empíricos avessos ao espírito da integração conceitual.

Habermas expõe, de modo sucinto, as dimensões do problema, quando explicita: (a) o deslocamento dos limites entre acaso e livre escolha afetam in totum a compreensão de agentes morais que se preocupam com suas existências;

20 DWORKIN. Sovereign Virtue: The Theory and Practice of Equality. Cambridge: Harvard University Press, 2000, p. 438. "The rhetoric of the European Parliament [...]".

Ibidem, p. 443. "[...] like the bizarre reference to 'fundamental human rights' in the European Parliament resolution I quoted earlier".

22 Ibidem. "What is the difference, after all, between inventing penicillin and using engineered and cloned genes to cure even more terrifying diseases than penicillin cures? What is the difference between setting your child strenuous exercises to reduce his weight or increase his strength and altering his genes, while an embryo, with the same end in view?"

23 HABERMAS. Op. cit., p. 53-54; versão portuguesa, p. 40-41.

24 DWORKIN. Op. cit., p. 443. "For that structure depends, crucially, on a fundamental distinction between what we are responsible for doing or deciding, individually or collectively, and what is given to

25 us, as a background against which we act or decide, but which we are powerless to change".

25 HABERMAS. Op. cit., p. 54. "[... wie wir uns anthropologisch als Gattungswesen verstehen". 
(b) o acaso remete à concreção entre a autocompreensão moral e o pano de fundo ético característico a uma espécie e (c) do acaso depende de certa forma a resposta à pergunta se podemos nos considerar como autores responsáveis de uma história de vida e nos respeitar uns aos outros como iguais por nascença. Nucleada a questão, o autor pondera para questionar: "Podemos considerar a autotransformação genética da espécie como caminho para incrementar a autonomia do indivíduo - ou iremos, ao seguir por esse caminho, solapar a autocompreensão normativa de pessoas que conduzem suas próprias vidas e se respeitam reciprocamente ${ }^{26}$ Habermas mitiga o rigor conseqüencial da alternativa, ao conceder que dela não resulta um argumento moral decisivo, mas tãosomente advém uma orientação amparada sobre uma forma ética mediada pela espécie.

Diferentemente do que ocorre com a matriz habermasiana, a posição liberal de eugenia é declaradamente diferenciadora. A racionalidade comunicativa do filósofo alemão funciona sem contradição e antítese, fincada que se encontra numa simetria relacional. Habermas só admite a eugenia negativa porque antecipa no embrião pré-pessoa um consenso entre seres livres e iguais. A eugenia positiva, em contrapartida, se lhe afigura inviável porque produz "uma relação interpessoal para a qual não há precedente", ${ }^{27}$ o que leva Dworkin a recorrer ao "Playing God". A eugenia de aperfeiçoamento condena, segundo Habermas, "a pessoa em questão a um determinado plano de vida, portanto, a restringe especificamente em sua liberdade de escolha de uma vida própria". ${ }^{28}$ Enquanto Dworkin observa que "[N]ão há nada em si mesmo errado com a ambição separada de fazer a vida das futuras gerações de seres humanos mais longas e mais cheia de talentos e, conseqüentemente, mais realizada", ${ }^{29}$ Habermas considera tal gesto uma interferência na contramão de nossa concepção simétrica de liberdade.

Para manter o argumento da simetria moral, a vida humana pré-pessoal é dialetizada negativamente pelo ex-frankfurtiano como universo moral - na condição de não ser um bem entre outros bens - e suprassumida positivamente como eticidade - na condição de autocompreensão ética da espécie e, simultaneamente, de nós próprios enquanto pessoas morais. Habermas coroa a indeclinável conexão dialética entre ambas as autocompreensões - da ética da espécie e das representações de nós mesmos - ao apostrofar:

26 Ibidem, p. 54-55. "Können wir die genetische Selbsttransformation der Gattung als Weg zur Steigerung der Autonomie des Einzelnen betrachten - oder werden wir auf diesem Wege das normative Selbstverständnis von Personen, die ihr eigenes Leben führen und sich gegenseitig die gleiche Achtung entgegenbringen, unterminieren?"

27 Ibidem, p. 109. "Eine solche Praxis würde zugleich eine interpersonale Beziehung erzeugen, für die es keinen Präzedenzfall gibt".

28 Ibidem, p. 105. "[...] wenn sie die betroffene Person auf einen bestimmten Lebensplan festlegt, jedenfalls in der Freiheit der Wahl eines eigenen Lebens spezifisch einschränkt".

29 DWORKIN. Op. cit., p. 452. "There is nothing in itself wrong with the detached ambition to make the lives of future generations of human beings longer and more full of talent and hence achievement". 
Nossas concepções e nossa forma de lidar com a vida humana pré-pessoal formam, por assim dizer, um ambiente estabilizador, do ponto de vista da ética da espécie, para a moral racional dos sujeitos de direitos humanos - um contexto de inserção que não pode ser rompido, se não quisermos que a própria moral venha a derrapar. ${ }^{30}$

Ao fazer da autocompreensão ética da espécie a condição privilegiada que garante a manutenção de nossa autocompreensão normativa de livres e iguais, Habermas engessa liberdade e igualdade com argamassas transformistas e condena a apreciação dos fundamentos morais da modernidade ao vôo da coruja de Minerva no anoitecer da era moderna. Na medida em que as objeções do conseqüencialismo são pertinentes, a autocompreensão ética da espécie não é adequada para prestar contas à autocompreensão moral moderna, uma vez que os processos de reprodução artificial, enfocados por Habermas, não equivalem a uma determinação ontológica do genoma humano, não impedem a pessoalidade da nova criatura, não prescrevem sua história de vida e tampouco sugerem uma mudança de espécie.

Comparado com as posições dworkinianas, o tipo de equivalência estabelecido por Habermas entre autocompreensão ética da espécie e autocompreensão moral da modernidade neutraliza a interdependência entre programa genético, fatores de meio e decisões pessoais. Dworkin lida, em contraposição, com uma gama de valores que oscilam entre as fronteiras do que alteramos e do que nos é dado cada vez aceitar. Os referenciais de mudança dworkinianos ostentam caráter empírico, ou seja, a mera possibilidade de viver dez vezes mais do que vivemos desloca os limites que estamos dispostos a aceitar, os riscos que aceitamos correr e a qualidade de vida que consideramos atrativa; de modo semelhante, a inovação científica das armas nucleares mudou as convicções dos cidadãos acerca dos limites fixados aos detentores do poder estatal em relação à vida de seus soldados em guerra e, por fim, nossas convicções sobre eutanásia e suicídio foram alteradas pelo poder da medicina em prolongar artificialmente a vida humana. "Minha hipótese", escreve Dworkin, "é que a ciência genética nos fez repentinamente cientes da possibilidade de um similar deslocamento moral, ainda que com dimensões bem maiores", ${ }^{31}$ um fenômeno que não constitui mera anomalia valorativa mas, ao contrário, ameaça de repente tornar obsoletos boa parte de nossos valores. ${ }^{32}$ "O terror que muitos de nós sentimos acerca do pensamento da engenharia genética", arremata o pensador estadunidense, "não é um medo daquilo que está errado; antes, é o medo de perder nossa segurança sobre o que é errado". ${ }^{33}$

30 HABERMAS. Op. cit., p. 115. "Unsere Auffassungen von - und unser Umgang mit - vorpersonalem menschlichem Leben bildet sozusagen eine stabilisierende gattungsethische Umgebung für die vernünftige Moral der Menschenreschtssubjekte - einen Einbettungskontext, der nicht wegbrechen darf, wenn nicht die Moral selbst ins Rutschen kommen soll".

31 DWORKIN. Op. cit., p. 444. "My hypothesis is that genetic science has suddenly made us aware of 32 the possibility of a similar though far greater pending moral dislocation".

32 Ibidem. "[...] and such a shift threatens [...] to make a great part of these [values] suddenly obsolete".

33 Ibidem. "The terror many of us feel at the thought of genetic engineering is not a fear of what is wrong; it is rather a fear of losing our grip on what is wrong". 
Considerando que a ética do discurso constitui a expressão mais moderna de busca por uma base convincente de validade situada além do pluralismo, a semântica habermasiana de fundamentação da natureza avança intuitivamente em direção a um ponto de referência neutro na autocompreensão da modernidade. À medida que Habermas insere a natureza humana numa zona de neutralidade argumentativa para alavancar objeções endereçadas à eugenia positiva, adquirem relevância percepções de si do ser humano como ser que é um corpo e, somente enquanto tal, reconhece a si mesmo como sujeito com início subtraído a qualquer manipulação genética. O filósofo alemão estabelece uma conexão intrínseca entre destino natural e consciência de ser sujeito autônomo como ser que é um corpo constituído por patrimônio genético intacto. Após haver-se referido ao nascimento, enquanto divisor de águas entre natureza e cultura, no sentido de um recomeço na acepção de H. Arendt, Habermas escreve:

Entendo essa alusão como se com o nascimento se estabelecesse uma diferenciação entre o destino determinado pela socialização de uma pessoa e o destino natural de seu organismo. Somente a referência entre natureza e cultura, entre inícios indisponíveis e a plasticidade de práticas históricas é que permite ao agente as auto-atribuições performativas, sem as quais ele não poderia se entender como iniciador de suas ações e pretensões. Com efeito, o ser si mesmo da pessoa exige um ponto de referência além dos laços de tradição e dos contextos de interação próprios de um processo de formação em que a identidade pessoal começa a se formar de acordo com a história de vida. ${ }^{34}$

O posicionamento caracteriza uma inexistente dicotomia entre natureza e cultura. O processo cultural não se insere num suporte natural virgem, intocável e incontestável. Já na procriação natural há modalidades de programação genética e a eugenia negativa constitui ela mesma uma intervenção na carga genética. Também a prática médica e a ciência biológica tradicionais objetivam o controle do destino natural do corpo. É o objetivo das pesquisas médicas e biológicas avançadas corrigir, sustar e inverter o destino natural de corpos que tendem inexoravelmente ao envelhecimento, às doenças e à inanição.

Habermas fica devendo dados empíricos, dependências causais e experiências fatuais que sustentem os nexos conceituais dos quais espera, segundo Kersting, "[...] que o programa do comando genético vá minar a igualdade moral das pessoas, restringir a autonomia dos afetados, ameaçar sua identidade pessoal e, com isso, destruir os fundamentos de ética pessoal e de nossa cultura democrática". 35

34 Ibidem, p. 102-103. "Ich verstehe diese Andeutung so, dass mit der Geburt eine Differenzierung einsetzt zwischen dem Sozialisationsschicksal einer Person und dem Naturschicksal ihres Organismus. Allein die Bezugnahme auf diese Differenz zwischen Natur und Kultur, zwischen unverfügbaren Anfängen und der Plastizität geschichtlicher Praktiken erlaubt dem Handelnden die performativen Selbstzuschreibungen, ohne die er sich selbst als Initiator seiner Handlungen und Ansprüche verstehen könnte. Denn das Selbstsein der Person erfordert einen Bezugspunkt jenseits der Traditionsstränge und Interaktionszusammenhänge eines Bildungsprozesses, in dem sich die

35 personale Identität lebensgeschichtlich erst formiert".

KERSTING. Der Hüter der Moderne - Jürgen Habermas über die Vergangenheit des Nationalstaates und die Zukunft der Natur, p. 92. "[...] dass das Programm der genetischen Steuerung die 


\section{Considerações finais}

A ladeira escorregadia (slippery slope) da qual Habermas fala, inicia bem antes da manipulação genética extracorporal. Justamente a autocompreensão da espécie sustentada por Habermas faz da tendência de subtrair-se ao próprio destino natural um dado antropológico irrenunciável, ou seja, o homem moderno se identifica com a luta sem fim contra o sofrimento físico, o destino natural da decadência corpórea e da morte certa. Aqui Dworkin tem a história humana a seu favor, quando observa: "Brincar de Deus é de fato brincar com fogo. Mas é isso que nós mortais temos feito desde Prometeu [...]. Nós brincamos com fogo e assumimos as conseqüências porque a alternativa é covardia perante o desconhecido". ${ }^{36}$

Para onde quer que se olhe, não há indícios de um colapso da natureza.

\section{Referências}

BADURA-LOTTER, Gisela. Embryonale Stammzellen - naturwissenschaftlicher Sachstand und ethische Analyse. In: ENGELS, E.-M./BADURA-LOTTER, G./SCHICTANZ, S. (Hrsg.). Neue Perspektiven der Transplantationsmedizin im interdisziplinären Dialog. Baden-Baden, 2000.

BAYERTZ, Kurt (Ed.). Sanctity of Life and Human Dignity. Dordrecht: Kluwer Academic Publishers, 1996.

BEECHER, Henry. "Ethics and clinical research". The New England Journal of Medicine. June, 16, 1966, p. 1354-1360.

BEAUCHAMP, Tom L. \& CHILDRESS, James F. Principles of Biomedical Ethics. 5. ed. New York: Oxford University Press, 2001.

BIRNBACHER, Dieter. Selbstbewusste Tiere und bewusstseinsfähige Maschinen - Grenzgänge am Rand des Personenbegriffs. In: STURMA, Dieter (Hrsg.). Person. Paderborn: Mentis, 2001, p. 301-321.

- \& WAGNER, Bernd. Risiko In: DÜWELL, Marcus \& STEIGLEDER, Klaus (Hrsg.). Bioethik. Eine Einführung. Frankfurt a/Main: Suhrkamp, 2003, p. 435-446.

CHARLESWORTH, Max. Bioethics in a Liberal Society. Cambridge: University Press, 1993.

DALL'AGNOLL, Darlei. Bioética: princípios morais e aplicações. Rio de Janeiro: DP\&A, 2004.

DAMSCHEN, Gregor \& SCHÖNECKER, Dieter (Hrsg). Der moralische Status menschlicher Embryonen. Berlin/New York: de Gruyter, 2005.

. The Embryonic Body and its Dignity. An Argument from Potentiality and Numerical Identity. In: Akten des 25. Internationalen Wittgenstein-Symposiums: 11.-17. August 2002. Sonderband. Kirchberg am Wechsel/Österreich.

ENGELHARDT, Jr. Hugo Tr. The Foundations of Bioethics. 2. ed. New York: Oxford University Press, 1996.

moralische Gleichheit der Personen aushöhlt, die Autonomie der Betroffenen einschränkt, ihre personale Identität ins Wanken bringt und damit die personenethischen Grundlagen unserer demokratischen Kultur zerstört".

36 DWORKIN. Op. cit., p. 446. "Playing God is indeed playing with fire. But that is what we mortals have done since Prometheus [...]. We play with fire and take the consequences, because the alternative is cowardice in the face of the unknown". 
Pluralismo moral e metafísico. Repensar a santidade da vida e da dignidade humanas. In: GARRAFA, Volnei \& PESSINI, Leo (Org.). Bioética: poder e injustiça. São Paulo: Loyola, 2003, p. 435-447.

EHRLICH, Paul, R. Human Natures: Genes, Culture and the Human Prospect. Washington: D.C.: Island Press, 2000

ENSKAT, Rainer. Pro Identitätsargument: Auch menschliche Embryonen sind jederzeit Menschen. In: DAMSCHEN, Gregor \& SCHÖNECKER, Dieter (Hrsg). Der moralische Status menschlicher Embryonen. Berlin/New York: de Gruyter, 2005, p. 102-127

FREITAS, Carlos M. Avaliação de riscos dos transgênicos orientada pelo princípio da precaução. In: VALLE, Sílvio \& TELLES, José Luiz (Org.). Bioética - Biorrisco: Abordagem transdisciplinar. Rio de Janeiro: Interciência, 2003, p. 113-142.

GEHLEN, Arnold. Moral und Hypermoral. Eine pluralistische Ethik. 5. Aufl. Wiesbaden, 1996.

GIACOIA Jr., Oswaldo. Um direito próprio da natureza? Notas sobre ética, direito e tecnologia. Fragmentos de Cultura, Goiânia, v. 14, n. 4, 2004, p. 637-654.

GROSSI, Miriam \& PORTO, Rozeli \& TAMANINI, Marlene (Org.). Novas tecnologias reprodutivas conceptivas: questões e desafios. Brasília: Letras Livres, 2003.

JONSEN, Albert R. Casuistry as Methodology in Clinical Ethics. In: Theoretical Medicine 12, 1991, 295-307.

HABERMAS, Jürgen. Die Zukunft der menschlichen Natur. Auf dem Weg zu einer liberalen Eugenik? Frankfurt a/Main: Suhrkamp, 2001.

HÖFFE, Otfried. Rechtspflichten vor Tugendpflichten. Das Prinzip der Menschenwürde im Zeitalter der Biomedizin. In: GEYER, Christian. Biopolitik. Die Positionen. Frankfurt a/Main: Suhrkamp, 2001.

. Medizin ohne Ethik? Frankfurt a/Main: Suhrkamp, 2002.

HOERSTER, Norbert. Ethik des Embryonenschutzes. Ein rechtsphilosophischer Essay. Stuttgart: 2004.

HONNEFELDER, Ludger. Pro Kontinuumsargument: Die Begründung des moralischen Status des menschlichen Embryos aus der Kontinuität der Entwicklung des ungeborenen zum geborenen Menschen. In: DAMSCHEN, Gregor \& SCHÖNECKER, Dieter (Hrsg). Der moralische Status menschlicher Embryonen. Berlin/New York: de Gruyter, 2005, p. 61-81.

KAUFMANN, Matthias. Contra Kontinuumsargument: Abgestufte moralische Berücksichtigung trotz stufendloser biologischer Entwicklung. In: DAMSCHEN, Gregor \& SCHÖNECKER, Dieter (Hrsg). Der moralische Status menschlicher Embryonen. Berlin/New York: de Gruyter, 2003, p. 83-98.

KERSTING, Wolfgang. Eugenia liberal? In: Liberdade \& liberalismo. Porto Alegre: Edipucrs, 2005.

Heiligkeit verleiht keine Rechte - Ronald Dworkin politische Philosophie der Abtreibung und Euthanasie. Gerechtigkeit und Lebenskunst. Philosophische Nebensachen. Paderborn: Mentis Verlag, 2005, p. 54-60.

. Der Hüter der Moderne - Jürgen Habermas über die Vergangenheit des Nationalstaates und die Zukunft der Natur. Gerechtigkeit und Lebenskunst. Philosophische Nebensachen. Paderborn: Mentis Verlag, 2005, p. 80-98

KNOEPFFLER, Nikolaus \& HANIEL, Anja (Hrsg.) Menschenwürde und medizinethische Konfliktfälle. Stuttgart: 2000

MOORE, George E. Principia ethica. Cambridge: Cambridge University Press 1993. 
MERKEL, Reinhard. Contra Speziesargument: Zum normativen Status des Embryos und zum Schutz der Ethik gegen ihre biologische Degradierung. In: DAMSCHEN, Gregor \& SCHÖNECKER, Dieter (Hrsg). Der moralische Status menschlicher Embryonen. Berlin/New York: de Gruyter, 2005, p. 35-58.

REICH, Warren. The Word 'Bioethics': Its Birth and the Legacies of Those who Shaped its Meaning." Kennedy Institute of Ethics Journal 4, 1994, p. 319-336.

ROTHMAN, David. Strangers at the Bedside: a history of how law and bioethics transformed medical decision making. New York: Basic Books, 1991.

SAMAJA, Juan. A reprodução social e a saúde: elementos metodológicos sobre a questão das relações entre saúde e condições de vida. Salvador: Casa da Qualidade Editora, 2000.

SCHOCKENHOFF, Eberhard. Pro Speziesargument: Zum moralischen und ontologischen Status des Embryos. In: DAMSCHEN, Gregor \& SCHÖNECKER, Dieter (Hrsg). Der moralische Status menschlicher Embryonen. Berlin/New York: de Gruyter, 2003, p. 11-33.

SILVA, Márcio B. Bioética e a questão da justificação moral. Porto Alegre: Edipucrs, 2004.

SCHÖNE-SEIFERT, Bettina. Contra Potentialitätsargument: Probleme einer traditionellen Begründung für embryonalen Lebensschutz. In: DAMSCHEN, Gregor \& SCHÖNECKER, Dieter (Hrsg.) Der moralische Status menschlicher Embryonen. Berlin/New York, W. de Gruyter, 2003, p. 169-185.

SOUZA, Draiton G. \& ERDTMANN, Bernardo (Org.). Ética e Genética II. Porto Alegre: Edipucrs, 2003.

SPAEMANN, Robert. Über den Begriff der Menschenwürde. In: SPAEMANN, Robert. Grenzen. Zur ethischen Dimension des Handelns. Stuttgart: Klett-Cotta, 2001, p. 107-122.

Gezeugt, nicht gemacht. Die verbrauchende Embryonenforschung ist ein Anschlag auf die Menschenwürde. In: GEYER, Christian (Hrsg.). Biopolitik. Die Positionen. Frankfurt a/Main: Suhrkamp, 2001.

Cotta, 1998.

Personen. Versuch über den Unterschied zwischen "etwas" und "jemand". Stuttgart: Klett-

STEIGLEDER, Klaus. Grundlegung der normativen Ethik. Der Ansatz von Alan Gewirth. Freiburg/München: Pieper, 1999.

STOECKER, Ralf. Contra Identitätsargument: Mein Embryo und ich. In: DAMSCHEN, Gregor \& SCHÖNECKER, Dieter (Hrsg). Der moralische Status menschlicher Embryonen. Berlin/New York: de Gruyter, 2005, p. 129-145.

STRONG, Carson. Ethics in Reproductive and Perinatal Medicine. A New Framework. New Haven, 1997.

UNNERSTALL, Herwig. Rechte zukünftiger Generationen. Würzburg: 1999.

VALLS, Álvaro. Da ética à bioéica. Rio de Janeiro: Campus: 2004.

VOLPATO DUTRA, Delamar J. Razão e consenso em Habermas. A teoria discursiva da verdade, da moral, do direito e da biotecnologia. Florianópolis: Editora da UFSC, 2005.

WIELAND, Wolfgang. Pro Potentialitätsargument: Moralfähigkeit als Grundlage von Würde und Lebensschutz. In: DAMSCHEN, Gregor \& SCHÖNECKER, Dieter (Hrsg.). Der moralische Status menschlicher Embryonen. Berlin/New York: de Gruyter, 2005, p. 149-168. 